\title{
DESIGN OF A TRITIUM PELLET INJECTOR FOR TFTR*
}

S. L. Milora, M. J. Gouge, P. W. Fisher, S. K. Combs, M. J. Cole, R. B. Wysor, D. T. Fehling,

C. R. Foust, and L. R. Baylor

Oak Ridge National Laboratory

Oak Ridge, TN 37831-8071

CONF-910968--17

G. L. Schmidt, G. W. Barnes, and R. G. Persing Princeton Plasma Physics Laboratory Princeton, NJ 08543
DE92 000737

\section{ABSTRACT}

The TFIR tritum pellet injector (TPI) is designed to provide a tritium pellet fueling capability with pellet speeds in the 1 - to $3 \mathrm{~km} / \mathrm{s}$-range for the TFTR D-T phase. The existing TFTR deuterium pellet injector (DPI) is being modified at Oak Ridge National Laboratory (ORNL) to provide a fourshoh tritium-compatible, pipe-gin configuration with three upgraded single-stage pneumatic guns and a two-stage light gas gun driver. The pipe gun concept has been qualified for tritum operation by the tritium proof-of-principle (TPOP) injector experiments conducted on the Tritium Systems Test Assembly (TSTA) at Los Alamos National Laboratory. In these experiments, tritium and D-T pellets were accelerated to speeds near $1.5 \mathrm{~km} / \mathrm{s}$. The TPI is being designed for pellet sizes in the range from 3.43 to $4.0 \mathrm{~mm}$ in diameter in arojtrarily programmable firing sequences at speeds up to approximately $1.5 \mathrm{~km} / \mathrm{s}$ for the three single-stage drivers and 2.5 to $3 \mathrm{~km} / \mathrm{s}$ for the two-stage driver. Injector operation will be controlled by a programmable logic controller (PLC).

\section{INTRODUCTION}

The TPI is a cryogenic pellet injector to be used prior to and during the D-T phase of TFTR. The injector shown in perspective in Fig. 1 will replace the eight-shot $\mathrm{DPI}^{1}$ at Bay $\mathrm{T}$ but will retain much of the injector facility currently in place. While the DPI formed pellets by an extrusion process, the TPI will form its four cylindrical pellets by the in situ condensation process. Two of these pellets will have diameters of $3.43 \mathrm{~mm}$; the other two, diameters of $4.0 \mathrm{~mm}$. The nominal aspect ratio is 1.25 . One of the $4-\mathrm{mm}$ guns will be equipped with a two-stage light gas gun driver, while the remaining three guns will operate with fast-acting electromagnetic propellant valves developed at ORNL. ${ }^{2}$ In the configuration described here, the single-stage guns are capable of producing velocities of $1.8 \mathrm{~km} / \mathrm{s}$ in deuterium and $1.5 \mathrm{~km} / \mathrm{s}$ in ritium.

Use of the TPI on TFTR will permit access to both a regime suitable for initial alpha particle physics studies and a regime suitable for studies of particle and energy confinement in high-density D-' $\mathrm{T}$ plasmas $\left[n_{\mathrm{e}}(0)=(1-5) \times 10^{20} \mathrm{~m}^{-3}\right)$. It will provide the capability for extending the supershot regime to density suitable for high- $Q$ operation and provide access to both the peaked-density-profile, pellet-fueled PEP regime ${ }^{4}$ and a regime of susiained high-density operation using multiple tritium pellets and ion cyclotron range of frequencies (ICRF) heating. The project is divided into two phases. Phase I activities allow the deuterium fueling capability to be used during 1992 operations, while the Phase II activities incorporate systems required for tritium operation and include an extended period of testing at the TFTR site, ending with the formation and acceleration of titium pellets in 1993.

\section{TPI SYSTEM DESIGN}

The TPI consists Gi several subsystems, which are shown in Figs. 1 and 2 and described below

\subsection{Injector}

The injector has a liquid-helium-cooled cryostat that provides cooling for pellet formation. The injector is located within the guard vacuum subsysten, and its design is based on the so-called "pipe-gun" concept, in which hydrogenic $(\mathrm{H}$, $D, T)$ pellets are formed by direct condensation in the gun barrel, a segment of which is held below the hydrogen triplepoint temperaure by contact with a liquid-helium-cooled block. Pellet length is controlled both by regulating the gas fill pressure and by establishing temperature gradients along the barrel tube with auxiliary heating collars. ${ }^{3}$ This design is ideal for tritium service because there are no moving pars in side the gun and because little additional tritium is required in the pellet production process. The injector uses four independent 1 -m-long gun barrel assemblies mounted around the perimeter of a single cryostat. The cryostats shown in Fig. 2 are based on designs used for injectors built for the Advanced Toroidal Facility and ihe Princeton Beta Experiment. ${ }^{5}$

Three of the barrel assemblies are coupled to an ORNLdesigned fast propellant valve (single-stage driver). This valve develops full pressure within $300 \mu \mathrm{s}$ and will operate with a supply pressure of up to 138 bar. The remaining barrel assembly is connected to the two-stage driver.

Experiments at the TSTA using a prototype tritium pellet injector have shown that the presence of noncondensible helium- 3 at levels above $0.005 \%$ prevents pellet formation by blocking the condensation of ritium in the pipe-gun freezing cell ${ }^{3}$ Since helium-3 occurs as a by-product of tritium decay, specific removal of residual helium -3 from the tritium feed gas to this level of purity is required. This removal is accom. plished using a cryogenic separator that is also located in the guard vacuum enclosure.

* Research sponsored by the Office of Fusion Energy. U.S. Department of Energy, undet contract DE-AC05-84OR21400 with Martin Marierta Fnergy Systems, Inc.

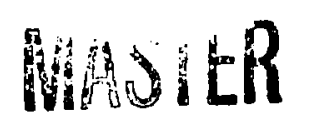




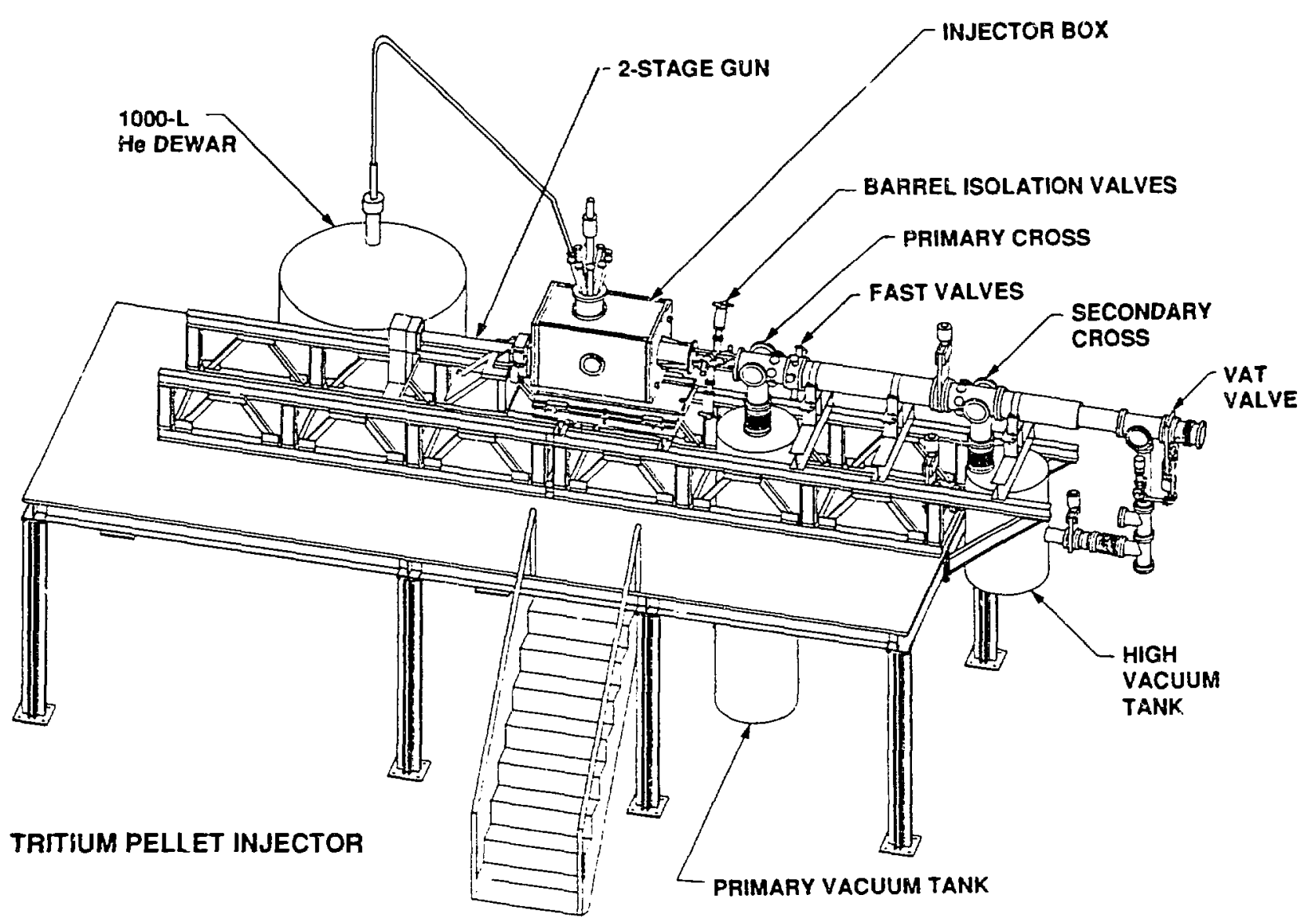

Fig. 1. Perspective view of the TPI installation on TFTR.

The tritium is purified by circulating the fuel charge through the separator, which freezes only the hydrogenic isotopes and leaves the noncondensitle helium -3 to be removed from the loop by a mechanical vacuum pump.

\subsection{Two-Stage Driver}

The two-stage driver subsystem provides the highpressure, high-temperature drive gas required to accelerate pellets to near $3 \mathrm{~km} / \mathrm{s}$. In the two-stage driver, moderatepressure helium propellant gas accelerates a piston to velo cities in the range of $100-200 \mathrm{~m} / \mathrm{s}$ in a thick-walled $(1.25-\mathrm{cm})$ pump tube. The piston in tum compresses adiabatically low pressure, romm-temperature iyddrogen Dropellant gas initially at about 1 bar. This hydrogen gas becomes the driving gas for the cryogenic pellet. At the high pressure reached following compression. the mechanical strength of the hydrogenic pellet becomes a design constraint and determines the maximum muzzle velocity, which is of order $2.5-3 \mathrm{~km} / \mathrm{s}$.

The TPI two-stage driver as shown in Fig. 2 consists of:

1. The 0.64-L first-stage reservoir, containing helium gas at a pressure up to 35 bar.
2. A $2.2-\mathrm{cm}$-diam orifice, meumatically actuated valve to accelerate the piston by releasing gas from the firsi-stage reservoir.

3. A $25-$ to $50 \mathrm{~g}$ titanium piston.

4. A cylindrical, $0.9-\mathrm{m}$-long, 2.54-cm-ID pump tube (the second stage), filled initially with hydrogen propellant gas at a pressure of $0.5-1$ har.

5. A high-pressure section that frovides additional strength at the end of the pump tube.

6. A bellows that isolates the two-stage driver and the guard vacuum chamber.

\subsection{Pellet Injection Line and Vacuum System}

The barrel isolation valve subsystem links the iriector with the primary vacuum subsystem. It consists of four vacuum valves and lour double-wall bellows units, one assembly per barrel. The valves, when closed, isolate the injecior frum the primary vacuum subsystem.

The primary vacuum subsystem links the injector with the high-vacuum subsystem. It consists of a stainless steel injection line contauning an array of four $8.0-\mathrm{mm}-\mathrm{ID}, 1.1-\mathrm{m}$ -

subsys high $v$ stainle m-long photog tion va

the pel also $\mathrm{co}$ most 0 peller 
long pellet guide tubes, four fast-acting (25-ms cycle time) conductance-limiting valves, a pellet ciagnostic station, an isolation valve at the connection to the high-vacuum subsystem, and a $0.71-\mathrm{m}^{3}$ stainless steel chamber. When pellets are fired, the primary vacuum subsystem absorbs most of the propellant gas used to accelerate the pellet.

The high-vacuum subsystem links the primary vacuum subsystem to the TFTR vacuum vessel through a region of high vacuum. The high-vacuum subsystem consists of a stainless steel injection line containing four $14.8-\mathrm{mm}-\mathrm{ID}, 1.0$ $\mathrm{m}$-long pellet guide tubes, a pellet diagnostic station for photography and pellet mass measurements, a system isolation valve and bellow's, and a ceramic break.

This portion of the subsystem ends with a connection to the pellet injector worus interface valve (TIV). The subsystem also contains a $0.265-\mathrm{m}^{3}$ stainless steel chamber that absorbs most of the residual propellant gas used to accelerate the pellet which is not absorbed by the primary vacuum system.
The TPI pumping subsysiem links the various TPI vacuum subsystems to the TFTR vacuum exhaust system, and, for Phase II tritium operations, to the gas holding tanks. The guard vacuum, primary vacuum, and high-vacuum sub systems are pumped by separate vacuum pumping systems, which sustain base pressures and provide pumping speeds appropriate to the different systems. Pumping for the guard vacuum subsystem is provided by a small turbopump backed by a rotary pump. Pumping for the primary vacuum subsystem is provided by a Roots blower backed by a rotary pump maintaining a base pressure of approximately $10^{-3}$ torr

Pumping for the high-vacuum subsystem is provided by a urbopump backed by a rotary pump maintaining a base pressure of approximately $10^{-1}$ tor. Exhaust from the two rotary pumps connected to the primary and high-vacuum subsystems is routed to a single vacuum line linked directly to the TFTR gas holding tanks (Phase II). Exhaust from the guard vacuum is routed to the diagnosuc vacuum exhaust and through this system to the gas holding tanks (Phase II)
- SECONDAAY

CONTAINMENT

(PHASE II)
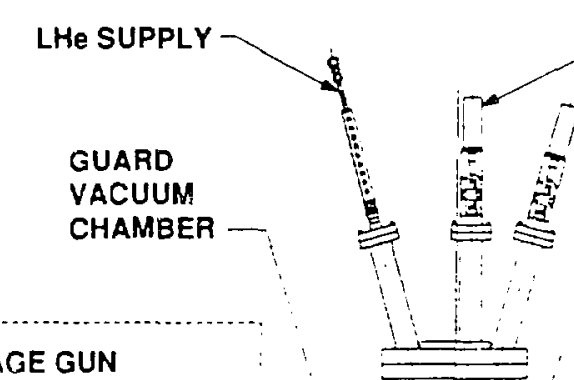

SINGLE STAGE GUN PORPELLANT VALVE (3) -

2-STAGE GUN PROPELLANT VALVE

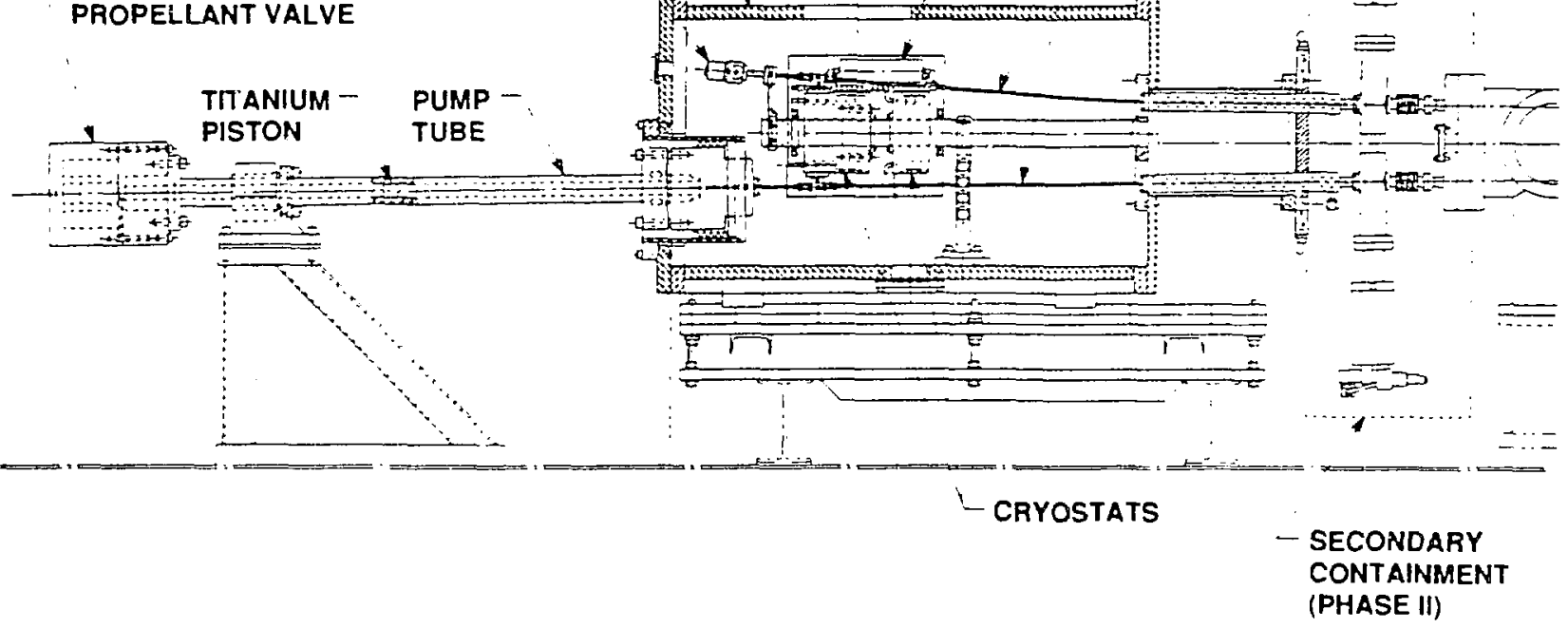

Fig. 2. The TPJ injector and two-stage light gas gun assembly

He 3 SEPARATOR

- BARREL ISOLATION VALVES (4)

I GUN BARRELS

(4)

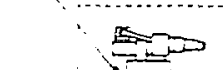




\subsection{Gas Supply and Manifold}

All nontritum working gases required for operation of the TPI will he supplied from a gas botte farm located in the test cell basement The gas supply system will provide deuterium at 3 bar, hydrogen at $150 \mathrm{bar}$, and helium at 70 bar and 8 bar (for pneumatic valve actuation). Tritium at 2.5 bar will be supplied from the tritium gas delivery system using a connection in the test cell near the pellet injector location. The tritium delivery lines will be doubly contained.

The gas manifold system consists of separate pellet fuel gas (D-T) and propellant gas feed systems. A diaphragm pump and a scroll pump are incorporated into the feed system for Phase $I$ to facilitate transfer of tritum to and from the injector. The gas manifold sy'stem will be located immediately behind the injector. The feed manifold will have the capability for mixing $D$ and $T$ gases to produce pellets of arbitrary

D: T content

\section{Liqued Helium Supply and Exhaust}

The liquid helium supply and exhaust subsystem supplies the refrigerant needed to cool both the injector and helium-3 separator cryostats to temperatures in the range $7-15 \mathrm{~K}$ at which deuterium and tritum peliets are formed.

The primary con.ponent of the TPI liquid helium subsystem will be a 1000 -L dewar located permanenty in the test cell at the pellet injector facility. This dewar will be connected to the neutral beam liquid helium distribution system by a fixed transfer line. The dewar will supply cold helium to the TPI cryostats and helium-3 separator located inside the guard vacuum chanber. Helium exhaust will be routed to the warm gas return line for the neutral beam refrigerator.

2.6 Secondary Containment and Tritium System Connections

The TPI consists of three classes of subsystems: (1) subsystems that are never exposed to tritium, (2) subsystems that are exposed to tritum but are passive in nature and are a]ways maintained at subatmospheric pressure, and (3) subsystems that contain tritium and either are maintained at pressures above atmospheric pressure or are expected to require maintenance (vacuum pumps, for exarnple). Containment of these three classes of subsystems will differ. Subsystems in class I will not use secondary containment and will not be linked directly to the tritum cleanup systems. Subsystems in class 2 will] not use secondary containment but will be linked to the trium cleanup systems. Subsystems in class 3 w'ill use secondary containment and will be linked to the tritium cleanup systems. The TPI components that will require secondary containment structures include the gas manifold, the two-stage driver, the injector, the barrel isolation valves, and the vacuum pumping system. The guard vacuum subsystem is itself a secondary containment sy'stem. 2.7 Conirol System

The TPI will be controlled by a PLC (Allen Bradley PLC $5 / 4 \cup$ ) located in the mezzanine beneath the injector. The operator will control the injector through a wouch panel color mimic screen provided with the PLC (one unit in the control room and one unit in the mezzanine for checkotii) or wit's a color mimic display/terminal interfaced to the existing pellet injector MicroVAX, which will have a communications link to the PLC. To the operator, the PLC will appear as a finitestate engine in which the injector will be in one of several defined states or modes. In each of these states the PLC will perform a series of operations (a procedure to enable the injectcr to go to the next state). The operator controls the system by setting the state to which the PLC is to go. All set points for temperatures and pressures within the injector are set automatically within the procedures by the PLC but can be modified by changing the preset values in the PLC, either through the touch panel via a pop-up keypad or through the MicroVAX interface. Firing of the injector is controlled by the TFTR fire sequencer, which is programmable through the MicroVAX. In addition to the automated operation of the TPI, the injector can be operated manually by controlling individual valves and changing individual set points.

\section{TWO-STAGE LIGHT GAS GUN DRIVER TESTS}

A prowtype two-stage light gas gun driver was consoucted to test piston longevity and to optimize operating parameters for the IPI application. Its design is based on the characteristics of the system described by Combs, ${ }^{6}$ which has been operated at speeds up $102.8 \mathrm{~km} / \mathrm{s}$ for $4-\mathrm{mm}$ deuterium pellets. The prowtype uses a specially developed pilot operated poppet valve to control the release of the helium propellant from the first-stage reservoir. This valve uses two helium-actuated, high-pressure bellows valves (Nupro HB series) to control the movement of the poppet. The same type of bellows valve is used to control the flow' of hydrogen propellant into the second-stage pump nube from a $30-\mathrm{cm}^{3}$ reservoir. These valves are indicated schematically in Fig. 3 by' $V_{2}$ and $V_{1}$

A typical operating sequence is shown for an initial firststage reservoi pressure of 20.1 bar, a second-stage fill pressure of $0.8 \mathrm{bar}$, and a piston mass of $44.8 \mathrm{~g}$. It can be seen from the time sequence that these valves typically exhibit a fixed delay of approximately $30-45 \mathrm{~ms}$. The reservoir valve, however, requires only $3.5 \mathrm{~ms}$ from the time that the poppet begins to move to open fully. This is indicated by the sharp rise of $\mathrm{P} 3$ at $t=83 \mathrm{~ms}$. The subsequent decrease of $\mathrm{P}_{2}$ and $\mathrm{P} 3$ results from movernert of the ficton. The piston uansit time for this case is less than $12 \mathrm{~ms}$, and the peak pressure P4 realized at the end of the piston travel is $=430$ bar. Subsequent cycles in the pressures are a result of oscillations of the piston within the pump tube. The gradual decrease of $P 3$ beginning at $t=145 \mathrm{~ms}$ results from opening of the vacium valve V3. The pressure behind the piston decays in $1 \mathrm{~s}$, at which time the piston is reseated at the beginning of the pump whe. This system has been operated for 1000 cycles at peak piston speeds of $170 \mathrm{~m} / \mathrm{s}$ without failure. The total piston wear over this period was measured to be $0.15 \mathrm{~mm}$. 


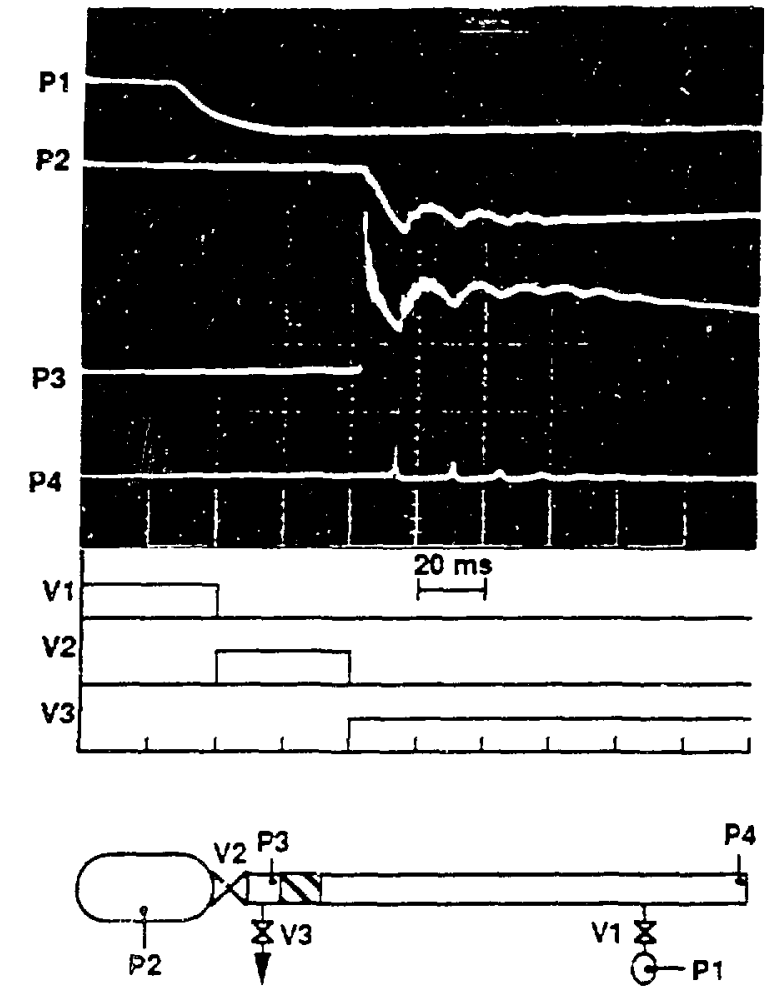

Fig. 3. Firing sequence for the two-stage light gas gun prototype and typical pressure response ai sevaral locations in the gun.

The performance of the two-stage driver has been modeled using the QLTCKGUN code. ${ }^{7}$ The resulis are shown in Fig. 4 for a case in which a 20 -mig tritium pellet is accelerated to a velocity of $2.7 \mathrm{~km} / \mathrm{s}$ in a path length of $1 \mathrm{~m}$ for an initial reservoir pressure of 16.6 bar. The relevant system parameters are plotted for tumes after release of the pelleh which is assumed to occur when the breech pressure reaches 48 bar (as detemined from tests of the TPOP device). This case exhibits relatively low piston velocities and moderate conditions at the breech. Moreover, the acceleration is gradual, as indicated by the moderate and relatively constant pressure predicted at the pellet base.

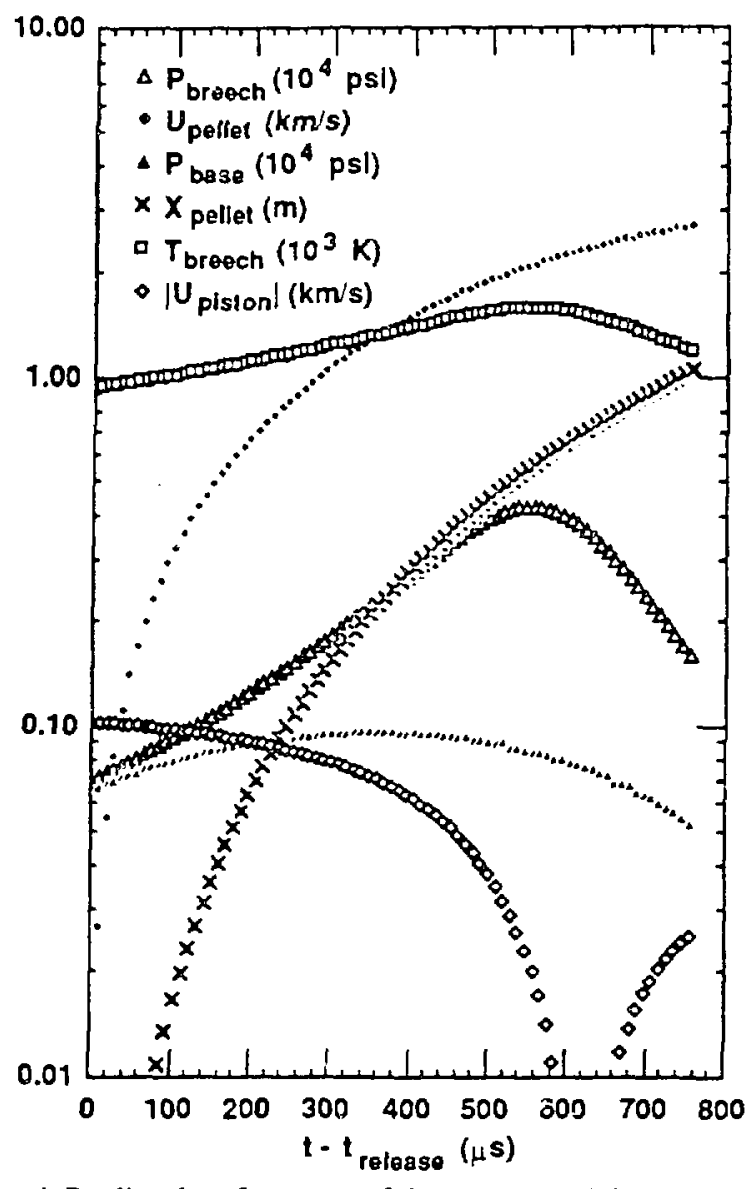

Fig. 4. Predicted performance of the two-stage light gas gun for 20-mg tritium pellet l ksi $=68.95$ bar.

\section{REFERENCES}

[1] S. K. Combs. S. L. Milora, C. R. Foust L. R. Bayjor. G. C Barber. R. D. Burris. P. W. Fisher. C. A. Foster, R. V. Luns ord G. L. Schmidh. D. D. Schuresko, T. Senko. R. C. Sharlever, W. D. Shipley. D. O. Sparks, K. A. Stewar, and R. B. Wysor, Rev. Sci. Instrum., vol. 58. p. 1195, 1987.

[2] S. L. Milora, S. K. Combs, and C. R. Foush Rev. Sci. Instrum., vol. 57. p. 2356, 1986

[3] P. W. Fisher. D. T. Fehling. M. J. Gouge, and S. L. Milora Proc. 13th Symp. Fusion Engr.. p. $1236\left(198^{\prime},\right)$

14] G. L. Schmidt and the JET team, in Plasma Physics and Con trolled Nucleas Fusion Research. Vol. I (LAEA, Vienna 1989) p. 215.

[5] A. L. Qualls. P. W. Fisher, J. B. Wilgen. D. D. Schuresko, D T. Fehling, and M. J. Gouge. Proc. 13 h Symp. Fusion Engr. p. 1244 (1989)

[6] S. K. Combs. C. R. Foust, M. J. Gouge, and S. L. Milora I. Vac. Sci. Technol. A, vol. 8, p. 1814 (1990).

[7] S. L. Milora, S. K. Combs, M. J. Gouge, and R. W. Kincaid Oak Ridge National Laboratong Repon ORNLTM-11561. September 1990

This repon was prepared as an account of work isponsored by an agency of the United States Government Netther the Unted States Government nor any agency thereof nor any of their employees, makes any warranty, express or implied, or assumes any legal liabuiny or responsi. bility for the accuracy. completeness, or usefulness of any information. appisratus, product, or process disclosed, or represents that its use would not infringe privately owned rights Refer. ence herem 10 any specific commercial product, process. or service by trade name, trademark, manufacturer, or otherwise does not necessarily constitute or imply its endorsement, recommendation. or favoring by the United States Government or any ayency thereof The views and opinions of authors expressed herein do not necessarily state or reflect those of the United States Goverament or any agency thereof. 